\title{
Prevalence and antimicrobial susceptibility of salmonella species isolate from slaughtered cows in Iraq
}

\author{
Arcan A.N. Al-Zubaid and Afaf Abdulrahman Yousif ${ }^{1 @}$ \\ ${ }^{1}$ Department of Internal Medicine, College of Veterinary Medicine, University of Baghdad, Iraq \\ afafa.rahman@yahoo.com \\ Accepted on 18/10/2012 \\ Summary
}

This study was planned to determine the prevalence and antimicrobial susceptibility of Salmonella spp. One hundred bovine with different age and both sexes at slaughterhouse were examined. Four hundred samples were collected from different internal organ (bile, Liver, spleen and mesenteric lymph nodes). Diagnostic study depended upon the morphological and cultural properties of the isolates on some selective media like Brilliant green, XLD, SS agar which used in addition to different biochemical tests, API-20E (Enterobacteriaceae Identification Kit.). Isolates were serotyped at the Central Public Health Laboratories (National Center of Salmonellae in Baghdad, Iraq). Eleven isolates consisting of Salmonella anatum (9.09\%), S.newport (27.27\%), S.enteritidis $(45.45 \%)$ and S.ohio $(18.18 \%)$. The percentage of infection were $3 \%$ in the mesenteric lymph node and liver, (4\%) in bile, and (1\%) in spleen. The antibiotic susceptibility pattern of Salmonella against 15 antimicrobial drugs revealed that all isolates were sensitive (100\%) to ciprofloxacin and amicacin. And most of isolates were resistance to cloxacillin, cefixime, amoxicillin. and gave intermediate results to neomycin, gentamycin, tetracycline and streptomycin.

Keywords: Salmonella, Prevalence, slaughtered cows, antimicrobial, susceptibility.

\section{Introduction}

Salmonellosis is a global problem for animals and human and the association of the disease between man and food animals has been investigated by many workers (1). Salmonella species are among the most important foodborne pathogens, leading to millions of cases of diarrheal illness, salmonellosis is associated with medium to severe morbidity and even mortality in farm animals representing major economic productivity loss in food and animal industries. Salmonella has been widely reported in cows (2, 3 and 4). Infection in animals is of importance because of the direct economic effect. Of even greater importance is that animals constitute a vast reservoir of these organisms for human infection (5). In humans, in addition to concern about foodborne zoonoses caused by Salmonella organisms, concern has also been raised about the impact of acquired antimicrobial resistance transferred among these organisms (6) which limits therapeutic options both in veterinary and public health practice.

This study aimed to determine the distribution of Salmonella spp in different internal organs of cows in slaughterhouse and determining the antimicrobial susceptibility of isolated Salmonella.

\section{Materials and Methods}

The study was performed on (100) cows with different ages and both sexes. Four hundred samples from internal organs were collected aseptically in sterile container (100) samples of each bile, mesenteric lymph nodes, spleen and liver. Samples were transferred to AL-Khairat Veterinary Laboratory immediately on cool box.

The isolation and biochemical identification of Salmonella was made according to (7). Each sample was cultured immediately on Tetrathionate broth and Brilliant green broth (HiMedia Laboratories Pvt.Ltd, India) and incubated at $37^{\circ} \mathrm{C}$ for $24 \mathrm{~h}$. A loopful of inoculum from each of enrichment cultures sample were inoculated on the surface of different type of medium containing Brilliant Green agar, XyloseLysine Deoxycholate agar (Oxoid, Hampshire, England), Salmonella-Shigella agar then incubated aerobically at $37^{\circ} \mathrm{C}$ for 24 h. for confirmation, five presumptive 
Salmonella colonies both from XLD agar, were selected and streaked onto the surface of pre-dried nutrient agar (Oxoid, Hampshire, England) plates and incubated at $37^{\circ} \mathrm{C}$ for 24 h. Pure cultures from the nutrient agar were used for biochemical confirmation (motility, triple sugar iron agar, indol, methyl red and citrate utilization tests, urea agar) were inoculated and incubated at $37^{\circ} \mathrm{C}$ for $24 \mathrm{~h}$.

Biochemical confirmation of Salmonella organisms were made according to (7). API20E (Enterobacteriaceae Identification Kit), this kit is a standardized colorimetric identification system utilizing conventional biochemical tests and carbohydrate utilization tests. The tests are based on the principle of $\mathrm{pH}$ change and substrate utilization. (8). Serotyping; All isolates were cultured on Kligler Iron media (HiMedia Laboratories Pvt.Ltd , India) for serotyping at the Central Public Health Laboratories (National Center of Salmonellae in Baghdad).

Each isolate was tested for susceptibility to fifteen commonly antimicrobials using the disk diffusion method according to the Kirby Bauer method (9). Well-isolated colonies were selected from brain heart infusion agar just the top of colonies touched and the growth transferred to tube containing 4-5ml of nutrient broth was inoculated and incubated at $37^{\circ} \mathrm{C}$ for $4 \mathrm{~h}$. Culture of each isolate was compared with McFarland tube NO 2. Muller Hinton agar plates (HiMedia, India) were inoculated by swabs immersed in each of the culture and held at room temperature for 30 minutes to allow drying. The disc was placed on to the agar surface using sterile forceps. Each disc was gently pressed with the point of sterile forceps to ensure complete contact with the agar surface cultures of Muller Hinton agar and incubated at $37^{\circ} \mathrm{C}$ for $20 \mathrm{~h}$. The diameters of the zones of inhibition were recorded to the nearest millimeter and classified as resistant, intermediate, or susceptible. Characterization of strains as sensitive or resistant was based on the size of inhibition zone around the disc compared with the interpretation standards provided by the manufacturers from Bionalyse, Turkey Company.
The categories susceptible or resistant were assigned on the basis of the critical points recommended by the Turkey Committee on Guidelines for susceptibility testing. Their concentration in the discs and their zone of inhibition in deciding susceptibility are given in (Table, 1).

\section{Results and Discussion}

The prevalence of Salmonella in animal and sample level was observed. At animal level, overall prevalence of 7\% (7 of 100) was bacteriologically positive for Salmonella. At sample level, Salmonella was observed with prevalence of $2.75 \%$ (Table,2). Detection of Salmonella from liver, mesenteric lymph nodes, bile, and spleen (each $\mathrm{n}=100$ ) with percentage rate of $3 \%, 3 \%, 4 \%$, and $1 \%$, respectively. Four different species of Salmonella were confirmed by national center of Salmonella in Baghdad (Table,3). Salmonella enteritidis and Salmonella newport were isolated at the highest frequency of $45.45 \%$ (5 of 11) and 27.27 (3 of $11 \%$ ) respectively, Salmonella ohio and Salmonella anatum were isolated at frequency of $18.18 \%$ and $9.09 \%$ respectively of the total isolates.

According to age of cows at slaughter house the results shows that Salmonella was highest $(7.70 \%)$ in $1.5-3$ year age group and lower percentage $(6.25 \%)$ in animals. More than 3 years, insignificantly difference between age group of cows (Table,4). Table, 5 revealed distribution of Salmonella species according to sex, six isolates from (56) samples recorded in male and (5) isolates from (44) recorded in female. insignificant difference between male and female.

The results of the present study showed that Salmonella were isolated at a percentage of $(7 \%)$ in cow at slaughter house and this is in agreement with the study of (2) who isolate Salmonella from $2 \%$ fecal, $2 \%$ rumen and $7.6 \%$ carcasses of cows at a commercial abattoir in Irish, while (10) recorded low percentage $(2.95 \%)$ of Salmonella from cow in Bangladesh authors (11) isolated Salmonella $(1.1 \%)$ from ground cattle beef samples. Other studies have also shown different results, (4) found a high percentage 
(38.89\%) of Salmonella in cow and apercentage of $(11.11 \%)$ from one hundred and eight samples (20 buffaloes and 88 cows) were collected from different Cairo slaughter house and abattoirs. Also (12) recorded isolation rate of salmonellae of $19 \%$ from carcass samples of cattle.

In the present study, four different species were confirmed which constituted about $(2.75 \%)$, this result similar to many researcher (13) who recorded different species in cows (S.typhimurium, 8; S.agona, 2; S.infantis, 1) and a study of other workers (2) who recorded three species in cows (S.typhinurium, S.agona, and S.dublin). Also in Egypt (4) found two species in cows (S.entritidisand S. typhimurium). While (14) isolated anew serovar from cattle in the Khartom State in Sudan the new serovar was named Salmonella umbadah and assigned as Salmonella enterica subspecies enterica on the basis of its biochemical characteristics. Salmonella Umbadah is now listed in the 9th edition of the Antigenic formulae of the Salmonella Serovars.

In Iraq (15) isolate S.typhimurium from bovine 320 fecal samples which collected from Cows of different ages and sexes present in farms and slaughter house in Diwaniya and Najaf provinces. Also (16) isolate S.typhimurium in a percentage of $4.5 \%$ from 150 sample isolate from calf and cows in some of Baghdad village and dairy cattle station.

The difference in the percentage of Salmonella in our study with others may be due to the difference in geographical region and the difference in temperature, humidity and ways of animal living and its management with the handling in abattoir.

In this study, higher percentage of Salmonella isolates from gall bladder from summation of Salmonella isolates in followed mesenteric lymph node, liver and spleen. A similar result has been recorded by (17) who found that the Salmonella organisms concentrated in gall bladder, liver, mesenteric lymph node and spleen in carrier animals. The results of present study according to sex show that the incidence of Salmonella in male is higher than in female, and this is agreement with, (18) who reported a percentage of Salmonella $(5 \%)$ of in female and higher in male $(8 \%)$ of the animals sampled at Uganda meat industries. While many studies indicate that the percentage of infection in female is higher than in male as in study by (15) who reported higher percentage of Salmonella $(13.5 \%)$ in female and lower in male $(7.7 \%)$.

The Antibiotic susceptibility pattern of Salmonella against the antimicrobial disc revealed that all isolates were resistant $(100 \%)$ to Cloxacillin, (91\%) of isolates are resistant to Cefixime and $(81.8 \%)$ of isolates are resistant to Amoxicillin. And all isolates sensitive $(100 \%)$ to Ciprofloxacillin and Amicacin (Table,6). The results of present study was in agreement with those of (18) who found that Salmonella was sensitive to Ciprofloxacin and Amicacinn, but disagreed about resistant to Gentamycin and Streptomycin. All isolates were susceptible to ciprofloxacin probably because the drug was relatively new on the market, fairly expensive and had not been used extensively in treatment of diseases in cattle. Resistance to ciprofloxacin also agreement with study of (19) who recorded that all isolates of cows showed $(100 \%)$ sensitive to ciprofloxacin. Ciprofloxacin showed a good antimicrobial activity against both human and cow isolates. Though no data has indicated this, the effectiveness of such drugs like ciprofloxacin may be because they are not widely used in countries like Iraq.

Most of the isolate in this study were resistant to erythromycin. Erythromycin is an old antibiotic belong to class macrolides that has been used to prevent infection caused by enteric pathogens, where almost $100 \%$ resistance have been reported from different parts of world (20). 
Table, 1: Antimicrobial discs used with their remarks

\begin{tabular}{|lllllll|}
\hline & & & & \multicolumn{2}{l}{ Diameter of zone $(\mathrm{mm})$} \\
No. & Antimicrobial agent & Code & Conc. & R & I & S \\
\hline 1 & Chloramphenicol & C & $\mathbf{3 0}$ & $\mathbf{1 2}$ & $\mathbf{1 3 - 1 7}$ & $\mathbf{1 8}$ \\
\hline 2 & Neomycin & N & $\mathbf{3 0}$ & $\mathbf{1 2}$ & $\mathbf{1 3 - 1 6}$ & $\mathbf{1 7}$ \\
\hline 3 & Suphamethoxazole & SMZ & $\mathbf{1 0 0}$ & $\mathbf{1 0}$ & $\mathbf{1 1 - 1 5}$ & $\mathbf{1 6}$ \\
\hline 4 & Gentamicin & CN & $\mathbf{1 0}$ & $\mathbf{1 2}$ & $\mathbf{1 3 - 1 4}$ & $\mathbf{1 5}$ \\
\hline 5 & Cefixime & CFM & $\mathbf{5}$ & $\mathbf{1 5}$ & $\mathbf{1 6 - 1 8}$ & $\mathbf{1 9}$ \\
\hline 6 & Erythromycin & E & $\mathbf{1 5}$ & $\mathbf{1 3}$ & $\mathbf{1 4 - 2 2}$ & $\mathbf{2 3}$ \\
\hline 7 & Ciprofloxacin & CIP & $\mathbf{5}$ & $\mathbf{1 5}$ & $\mathbf{1 6 - 2 0}$ & $\mathbf{2 1}$ \\
\hline 8 & Kanamycin & K & $\mathbf{3 0}$ & $\mathbf{1 3}$ & $\mathbf{1 4 - 1 7}$ & $\mathbf{1 8}$ \\
\hline 9 & Amoxicillin & AX & $\mathbf{2 5}$ & $\mathbf{1 3}$ & $\mathbf{1 4 - 1 7}$ & $\mathbf{1 8}$ \\
\hline 10 & Streptomycin & S & $\mathbf{1 0}$ & $\mathbf{1 1}$ & $\mathbf{1 2 - 1 4}$ & $\mathbf{1 5}$ \\
\hline 11 & Tetracycline & TE & $\mathbf{3 0}$ & $\mathbf{1 4}$ & $\mathbf{1 5 - 1 8}$ & $\mathbf{1 9}$ \\
\hline 12 & Amicacin & AK & $\mathbf{3 0}$ & $\mathbf{1 4}$ & $\mathbf{1 5 - 1 6}$ & $\mathbf{1 7}$ \\
\hline 13 & Trimethoprim & TMP & $\mathbf{5}$ & $\mathbf{1 0}$ & $\mathbf{1 1 - 1 5}$ & $\mathbf{1 6}$ \\
\hline 14 & Cloxacillin & CX & $\mathbf{1}$ & $\mathbf{1 4}$ & $\mathbf{1 5 - 1 8}$ & $\mathbf{1 9}$ \\
\hline 15 & Nitrofurantoin & F & $\mathbf{3 0 0}$ & $\mathbf{1 4}$ & $\mathbf{1 5 - 1 6}$ & $\mathbf{1 7}$ \\
\hline & & & & & &
\end{tabular}

Table, 2: Percentage of infections with Salmonella in cow

\begin{tabular}{|lllllll|} 
Location & $\begin{array}{l}\text { No. of } \\
\text { cow }\end{array}$ & $\begin{array}{l}\text { No. of } \\
\text { affected } \\
\text { animal }\end{array}$ & $\%$ & $\begin{array}{l}\text { No. of } \\
\text { sample }\end{array}$ & $\begin{array}{l}\text { No. of sample } \\
\text { positive to } \\
\text { Salmonella }\end{array}$ & $\%$ \\
\hline Slaughterhouse & $\mathbf{1 0 0}$ & $\mathbf{7}$ & $\mathbf{7 \%}$ & $\mathbf{4 0 0}$ & $\mathbf{1 1}$ & $\mathbf{2 . 7 5 \%}$ \\
\hline
\end{tabular}

Table, 3: Number and distribution of Salmonella species in different organs

\begin{tabular}{|rlllll|}
\hline $\begin{array}{c}\text { No. of } \\
\text { animal }\end{array}$ & Liver & Spleen & Bile & MLN & $\begin{array}{l}\text { No. of } \\
\text { isolates }\end{array}$ \\
\hline 1 & S.anatum & - & - & - & 1 \\
\hline 2 & S.newport & - & - & S.newport & 2 \\
\hline 3 & - & S.newport & - & - & 1 \\
\hline 4 & - & - & S.enteritidis & S.enteritidis & 2 \\
\hline 5 & - & - & S.ohio & S.ohio & 2 \\
\hline 6 & S.enteritidis & - & S.enteritidis & - & 2 \\
\hline 7 & - & - & S.entritidis & - & 1 \\
\hline Total & $\mathbf{3}$ & 1 & 4 & 3 & 11 \\
\hline
\end{tabular}

Table, 4: Distribution of Salmonella isolate according toage of animals

\begin{tabular}{|ccccc|}
\hline Cow age & $\begin{array}{c}\text { No.of animal } \\
\text { examined }\end{array}$ & $\begin{array}{c}\text { No. of effected } \\
\text { animal }\end{array}$ & $\%$ & $\mathrm{X}^{2}$ value \\
\hline 6month 1.5years & 45 & 3 & $\mathbf{6 . 6 6 \%}$ & $\mathbf{7 . 7 0 \%}$ \\
\hline 1.5years-3 years & 39 & 3 & $\mathbf{C a l} \mathbf{X}^{2}=\mathbf{0 . 0 5}$ \\
$\mathbf{P}=\mathbf{0 . 9 7 2}$ \\
$\mathbf{d f}=\mathbf{2}$
\end{tabular}

Chi =1.2 non-significant difference between age group of cows. 
Table, 5: Distribution of Salmonella species according to sex of animal

\begin{tabular}{|c|c|c|c|c|}
\hline Cow sex & No.of examine animal & No. of affected animal & $\%$ & \multirow{4}{*}{$\begin{array}{l}\text { Cal } X^{2}=0.004 \\
P=0.95 \\
d f=1\end{array}$} \\
\hline Male & 56 & 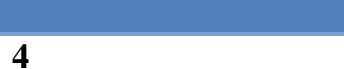 & $7.14 \%$ & \\
\hline Female & 44 & 3 & $6.81 \%$ & \\
\hline Total & 100 & 7 & $7 \%$ & \\
\hline
\end{tabular}

Chi $=0.7 n o n-s i g n i f i c a n t$ difference between male and female.

Table, 6: Antibiotic susceptibility pattern of Salmonella

\begin{tabular}{|c|c|c|c|c|c|c|c|c|}
\hline No. & Antibiotics used & $\begin{array}{l}\text { Total } \\
\text { No. of } \\
\text { isolate }\end{array}$ & $\mathbf{R}$ & $\%$ & $\mathbf{I}$ & $\%$ & $\mathbf{S}$ & $\%$ \\
\hline 1 & Chloramphenicol & 11 & 6 & $54.6 \%$ & $\mathbf{0}$ & $0 \%$ & 5 & $45.4 \%$ \\
\hline 2 & Neomycin & 11 & 3 & $27.2 \%$ & 4 & $36.4 \%$ & 4 & $36.4 \%$ \\
\hline 3 & Suphamethoxazol & 11 & 8 & $72.7 \%$ & $\mathbf{0}$ & $0 \%$ & 3 & $27.3 \%$ \\
\hline 4 & Gentamicin & 11 & 6 & $54.6 \%$ & 4 & $36.4 \%$ & 1 & $9 \%$ \\
\hline 5 & Cefixime & 11 & 10 & $91 \%$ & $\mathbf{0}$ & $0 \%$ & 1 & $9 \%$ \\
\hline 6 & Erythromycin & 11 & 8 & $72.7 \%$ & $\mathbf{0}$ & $0 \%$ & 3 & $27.3 \%$ \\
\hline 7 & Ciprofloxacin & 11 & 0 & $\mathbf{0 \%}$ & $\mathbf{0}$ & $0 \%$ & 11 & $100 \%$ \\
\hline 8 & Kanamycin & 11 & 5 & $45.4 \%$ & 2 & $18.2 \%$ & 4 & $36.4 \%$ \\
\hline 9 & Amoxicillin & 11 & 9 & $81.8 \%$ & $\mathbf{0}$ & $0 \%$ & 2 & $18.2 \%$ \\
\hline 10 & Streptomycin & 11 & $\mathbf{0}$ & $\mathbf{0 \%}$ & 11 & $100 \%$ & $\mathbf{0}$ & $0 \%$ \\
\hline 11 & Tetracycline & 11 & 5 & $45.4 \%$ & 4 & $36.4 \%$ & 2 & $18.2 \%$ \\
\hline 12 & Amicacin & 11 & $\mathbf{0}$ & $\mathbf{0 \%}$ & $\mathbf{0}$ & $0 \%$ & 11 & $100 \%$ \\
\hline 13 & Trimethoprim & 11 & $\mathbf{0}$ & $0 \%$ & 1 & $9 \%$ & 10 & $91 \%$ \\
\hline 14 & Cloxacillin & 11 & 11 & $100 \%$ & $\mathbf{0}$ & $0 \%$ & $\mathbf{0}$ & $0 \%$ \\
\hline 15 & Nitrofurantoin & 11 & 3 & $27.3 \%$ & $\mathbf{0}$ & $0 \%$ & 8 & $72.7 \%$ \\
\hline
\end{tabular}

References

1. Ribeiro, M.G.; Langoni, H.; Jerez, J.A.; Leite, D.S.; Ferreira, and Gennari, S.M. (2000). Identification of entero pathogens from buffalo calves with and without diarrhea in the Ribeira Valley, Brazilian J. Vet. Res. Anim. Sci., 37: 172-178.

2. McEvoy, J.M.; Doherty, A.M.; Sheridan, J.J.; Blair, I.S.; and McDowell, D.A. (2003). The prevalence of Salmonella spp in bovine fecal, rumen and carcass samples at a commercial abattoir. J. Appl. Microbiol., 94: 693-700.

3. Alemu, S. and Zewde, M.B. (2012). Prevalence and antimicrobial resistance profiles of Salmonella enterica serovars isolated from slaughtered cattle in BahirDar, Ethiopia, Trop. Anim. Health Prod., 44: 595600.

4. Hassanain, A.; Hassanain, M.A.; Shaapan, R.M.; Fadaly, H.A. and Barakat, A.M. (2010). Diagnosis of Eygyptian Bovine Meat Borne Zoonosis. J. Am. Sci., 6(12): 15261533.
5. Libby, J.S.; Halsey, A.; Altier, C.; Potter, J. and Gyles, L.C.; (2004). Salmonella. In: L.C. Gyles, F.J. Prescott, G. J. Snoger, and O.G. Thoen, (Eds), Pathogenesis of Bacterial Infections in Animals, 3rd ed. Blackwell Publishing, USA; PP: 143-167.

6. Dargatz, D.A.; Fedorka-Cray, P.J.; Ladely, C.A.; Kopral, C.A.; Ferris, K.E. and Headrick, M.L. (2003). Prevalence and antimicrobial susceptibility of Salmonella spp. isolates from US cattle in feedlots in 1999 and 2000. J. Appl. Microbiol., 95: 753-761.

7. Quinn, P.J.; Carter, M.E.; Markey, B. and Carter, G.R. (2004). Clinical Veterinary Microbiology. $6^{\text {th }}$ Ed. Mosby an imp. Wolf, London, PP: $66-85$.

8. Thangamaalr, A.; Ramesh, G.; Subramanian, S. and Ahalingam C.G. (2009). Use of biochemical kits for characterization of Enterobacteriaceae from the gut of silk worm, Bombyx mori L. Karnataka J. Agric. Sci., 22 (3): 514-516. 
9. Bauer, A.W.; Kirby, W.M.; Sherris, J.C. and Turck, A. (1966). Antibiotic susceptibility testing by a standardized single disc method. Am. J. Clin. Pathol., 45(5): 493 465.

10. Sen, M.M.; Chakraborty, H.; Rahman, A. and Hossain, A. (1988). Carrier cattle and buffaloes in Bangladesh. Bangl. Vet., 5(1): 23-25.

11. Phillips, D.; Jordan, D.; Morris, S.; Jenson, I. and Sumner, J. (2008). A national survey of the microbiological quality of retail raw meats in Australia. J. Food Prot., 71: 1232-1236.

12. Beach, J.C.; Murano, E.A. and Cuff G.R. (2002). Serotyping and antibiotic resistance profiling of Salmonella in feedlot and no feedlot beef cattle. J. Food Prot., 65: 16941699.

13. Abouzeed, Y.M. (1998). Characterization of Salmonella isolates from beef cattle, broiler chicken and human sources on Prince Edward Island. Master Thesis, College of Veterinary Medicine- University of Prince Edward Island.

14. Elsafi, H.E; Nor Elmadiena, M.M.; El Hussein, A.A.; Siddig, M.A.; Muckle, A.C.; Cole. L.; Wilkie, E. and Mistry, K. (2009). Salmonella Umbadah: A new Salmonella serovar isolated from cattle in Sudan. Trop. Anim. Health Prod., 41:1605-1606.

15. Al-Karawiy, H.A. (2008). Isolation and identification of Salmonella typhimurium and detection of gene encoded Type -1-fimbriae by using Polymerase Chain Reaction. M.Sc. Thesis, Vet. Med. College/ Basrah University - Iraq.

16. Al-Rawi, Z.S. (2003). Diagnostic study of S.typhimurium in patient and cattle. MSc. Thesis, College of Veterinary Medicine University of Baghdad.

17. Humphrey, T.J. (2000). Public Health Aspects of Salmonella Infection. In: Salmonella in Domestic Animals. Edited by Wray, C. and Wray, A. International CAB. PP: $245-263$.

18. Majalija, S; Ezama, A. and Vudriko, P. (2010). Faecal shedding of multidrug resistant Salmonella in slaughter Ankole cattle in Kampala city, Uganda. Afri. J. Anim. Biomed. Sci., 5(3): 21-27.

19. Addis, Z; Kebede, N; Worku, Z; Gezahegn, H; Yirsaw, A. and Kassa, T. (2011). Prevalence and antimicrobial resistance of Salmonella isolated from lactating cows and in contact humans in dairy farms of Addis Ababa: a cross sectional study. BMC Infec. Dis., 11: 222.

20. Harakeh, S.; Yassine, H.; Gharios, M.; Barbour, E.; Hajjar, S.; El-Fadel, M.; Toufeili, I. and Tannous, R.(2005). Isolation, molecular characterization and antimicrobial resistance patterns of Salmonella and Escherichia coli isolates from meat-based fast food in Lebanon. Sci. Total Environ., 341: 33-44.

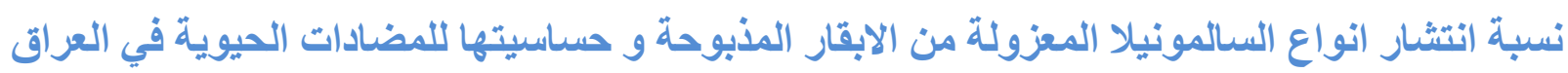

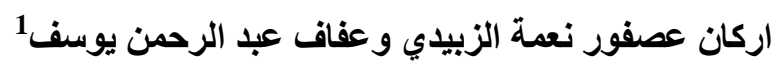

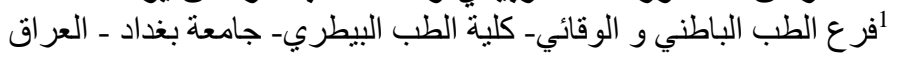

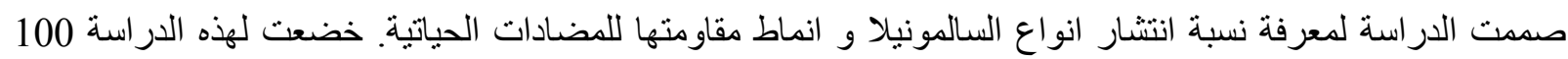

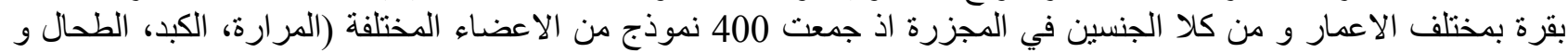

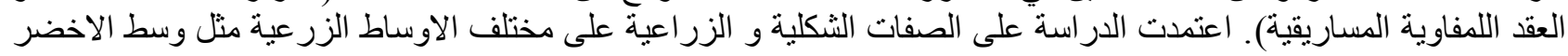

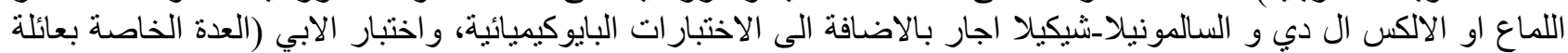

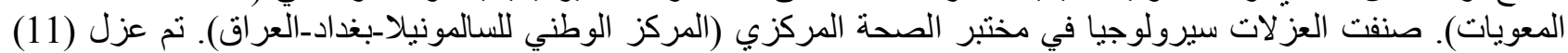

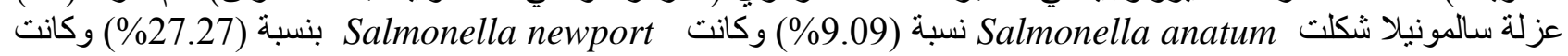

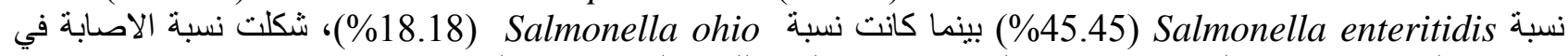

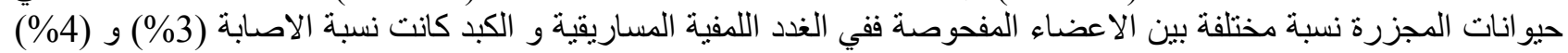

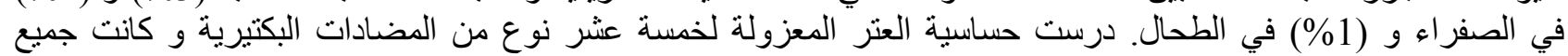

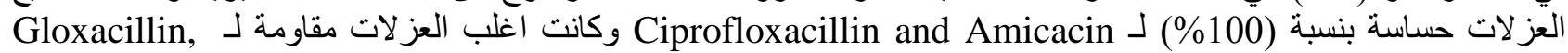
Neomycin, Gentamycin, Tetracyclin and وكذلات كانت متوسطة المقاومة لكل من Cefotaxim and amoxicillin 